\title{
article
}

\section{Digital platforms for the co-creation of public value}

\author{
Albert Meijer, a.j.meijer@uu.nl \\ Utrecht University School of Governance, The Netherlands \\ Wouter Boon, w.p.c.boon@uu.nl \\ Copernicus Institute Utrecht University, The Netherlands
}

\begin{abstract}
This article provides a theoretical understanding of the potential contribution of digital platforms to the co-creation of public value. On the basis of insights from different academic disciplines, a layered model is developed for the relations between technology, governance, users and societal outcomes. The theoretical model proposes that these layers can result in basic configurations consistent combinations of the four elements - but also hybrid configurations. We identify three basic configurations: (1) a closed platform controlled by a private sector organisation, (2) an open platform controlled by a government organisation and (3) an open platform run by a civil society organisation. The configurations are illustrated with examples of digital platforms from all over the world. The configurational understanding of digital platforms for the co-creation of public value provides the basis for a systematic analysis of these rapidly growing practices in countries around the world.
\end{abstract}

Key words co-creation $\bullet$ digital platform $\bullet$ e-government $\bullet$ public value $\bullet$ user incentives $\bullet$ modes of governance

To cite this article: Meijer, A. and Boon, W. (2021) Digital platforms for the co-creation of public value, Policy \& Politics, vol 49, no 2, 231-248, DOI: 10.1332/030557321X16115951032181

\section{Introduction}

The private sector is changing towards a new model of production. Industrial companies, such as Ford, are no longer seen as the key to economic progress and digital technology companies, such as Uber, are dominating discussions about organisational models (Kenney and Zysman, 2015; Acquier et al, 2017). These tech companies rely on the platform logic for the production of services: the platform provides the basis for many-to-many relations between providers and consumers through information about preferences and systems of trust.

Central to the platform organisations is their capacity to connect numerous users and coordinate their interactions. In that sense, platform organisations rely on a radically 
different organisational model than traditional organisations (Hagiu and Wright, 2015; Scaraboto, 2015). The hierarchic and sequential logic of the Fordist model is replaced by a horizontal and parallel logic. This mode of organisation is facilitated by platform technologies which process the variety of interactions between the many users accurately and fast.

A big question is whether this new mode of production also works for the public sector.This article explores the potential value of digital platforms for the co-creation of public value. In essence, the co-creation of public value entails the collaboration between a broad group of stakeholders to develop innovative solutions for societal problems (Torfing et al, 2019: 797). Co-creation is a radical break away from the traditional government-centric mode of idea generation, which is why Torfing et al (2019) refer to it as a new public administration paradigm. The platform model appears to have a great fit with the idea of co-creation as a new paradigm since it facilitates the interactions between a large number of actors to generate innovative ideas (Torfing et al, 2019).

From various angles, scholars are trying to capture the new paradigm (O'Reilly, 2010;Al-Ani, 2017). In recent publications, Ansell and Miura (2019) present a highly relevant discussion of the relation between platforms and governance and Meijer et al (2019) use the term 'open governance' for a similar type of analysis. Both articles put emphasis on organisational features of platforms but do not specifically analyse the role of platforms in co-creation and fail to analyse how platforms contribute to public value. For this reason, this article specifically focuses on the relation between co-creation on digital platforms and public value (Moore, 1995; Bryson et al, 2014). This article builds on and extends the previous analyses of digital platforms in the public sector to develop a theoretical understanding of digital platforms for co-creation of public value.

The leading question for this exploratory article is: how can we understand the potential contribution of digital platforms to the co-creation of public value? It is our ambition to use insights from different academic disciplines to develop a model for understanding the relations between technology, governance, users and societal outcomes. To this end, the article does not only build upon literature from public administration (Alford, 2009; Ansell and Miura, 2019; Meijer et al, 2019; Torfing et al, 2019; Lember et al, 2019) but also builds upon three bodies of literature that seem particularly relevant to this topic: the literature on e-government (Janssen and Estevez, 2013), user innovation (Von Hippel, 2005) and public value (Moore, 1995; Alford and Hughes, 2008; Bryson et al, 2014).

This article starts with a definition of digital platforms for the co-creation of public value, which systematically addresses the various elements (the second section). In the third section, we present four different perspectives on digital platforms for the co-creation of public value: the technological perspective, the governance perspective, the user perspective, and the societal perspective. These theoretical perspectives are used to develop a multi-layered perspective on digital platforms for the co-creation of public value, which presents technology, governance, users and societal value as layers (the fourth section). We end this article with conclusions about the potential contribution of digital platforms to the co-creation of public value and an agenda for future research (the fifth section). 


\section{Defining digital platforms for co-creation of public value}

\section{Digital platforms}

Digital platforms can be understood as virtual locations on which users and suppliers of products or services communicate and conduct transactions (Kenney and Zysman, 2016). Much of the literature emphasises that platforms are not only technological systems but also a new organisational model: a vertical and sequential way of doing tasks is replaced by a horizontal and parallel approach. Janssen and Estevez (2013: S2) stress that platforms are a way to involve a highly complex landscape consisting of many interacting, networked and collaborative actors. Platforms can be defined by two characteristic features.

First, platforms have a technological component as they are built on advances in networked software to create virtual spaces (Bekkers, 2003). The technological architecture is of modular nature and contains core and peripheral elements (Gawer, 2014) which together form a platform ecosystem (Kenney et al, 2019). At the same time, the technological structure establishes rules and parameters whereby, de facto, it creates a regulatory framework to which platform participants are bound (van Dijck, 2013). Platforms owners have a great deal of power as they establish the level of information transparency, the interactions rules, privacy rules and so on.

Second, platforms are locations facilitating exchange and transaction between users. Bekkers (2003) describes platforms as a space for the sharing of information and knowledge, as well as a virtual meeting place for communication and interaction. In this vein,Ansell and Miura (2019:263) define platforms as providing,'various kinds of resources for its affiliates or users to productively and flexibly organize'. Economists perceive platforms as two-sided markets because both supply and demand join the market to participate (Rochet and Tirole, 2003). The two sides of the marketplace can be formed by homogenous (for example, peer-to-peer) or heterogenous (for example, business-to-consumer) actors.

\section{Co-creation}

The term co-creation originates from marketing studies in which emphasis was on the interaction between firms and their consumers in developing services (Prahalad and Ramaswamy, 2004). The level of consumer involvement ranges from product or service feedback to active contribution to innovation processes. Von Hippel (2005) focuses on users coming up with new ideas for products, building prototypes, and even bringing products to market either with or without commercial firms.

In the public administration literature, co-creation is used in a way that is more closely related to the literature on social innovation, as both concepts present strategies for generating new solutions for public problems. However, Torfing et al (2019: 803) notice that there is a crucial difference, while social innovation mostly focuses on the participation of civil society, co-creation captures the engagement of the plurality of public and private actors in the generation of solutions.

The emphasis on co-creation in the public sector can be positioned as a response to the pitfalls and limitations of new public management. The conceptualisation of the citizen as a recipient of public services helped to strengthen the focus on customer satisfaction but failed to acknowledge the active role of citizens in the innovation of 
public services (Osborne, 2018). The perspective of co-creation acknowledges that citizens do not only consume services but can play an active role in innovating and re-structuring public services.

Torfing et al (2019: 798) correctly note that co-creation as such is not new since stakeholders have been engaged in the generation of new ideas for a long time. At the same time, this was never part of the classical view on government being the sole provider of public goods. Torfing et al (2019: 798) highlight that the central position that co-creation has obtained as a strategy for realising new solutions is new: 'co-creation replaces public service monopolies and public-private competition with multi-actor collaboration and, in doing so, it transforms the entire perception of the public sector' (Torfing et al, 2019: 798).

This article will follow the definition of co-creation in the public sector that Torfing et al (2019: 802) formulated. On the basis of an extensive review of the literature:

a process through which two or more public and private actors attempt to solve a shared problem, challenge, or task through a constructive exchange of different kinds of knowledge, resources, competences, and ideas that enhance the production of public value in terms of visions, plans, policies, strategies, regulatory frameworks, or services, either through a continuous improvement of outputs or outcomes or through innovative step-changes that transform the understanding of the problem or task at hand and lead to new ways of solving it.

\section{Public value}

The concept of public value helps to differentiate between private benefits (which are dominant in the marketing literature on co-creation) to contributions to society (which is the focus in public administration). The literature on public value is rapidly expanding since it is seen as a fruitful perspective on assessing public performance. In a broad sense, public values are those outcomes that are seen as of worth, utility or importance by the public. Public values include outcomes directly connected to governance such as fairness or democracy but also societal desirable outcomes such as health, security or sustainability (Bryson et al, 2014).

Traditionally, public value was seen as the result of government actions but it is increasingly seen as the outcome of interactions in complex societal systems (Alford and Hughes, 2008). To position our understanding of digital platforms for the co-creation of public value, we emphasise two aspects: (1) the public sector consists of more than just the government, and (2) the public sector is not only about government policies but also about public problems in a broad sense. Both aspects are integral to the so-called governance paradigm that challenges the central role of governments and helps to conceptualise the production of public value as the result of collaborative action (Torfing et al, 2019; Meijer et al, 2019).

First, the governance paradigm highlights that solutions to public value are not only produced by government but often emerge from complex interactions between governmental organisations, private sector actors and civil society actors (Koppenjan and Klijn, 2004). This means that digital platforms for co-creation in the public sector are not limited to government-initiated platforms. Private sector platforms and civil 
society platforms can also provide contributions to the co-creation of public value. We will illustrate this with two examples.

An example of a private sector platform contributing to the co-creation of public value, is 'Battle of Concepts' in the Netherlands. This site presents an online idea contest. Public and private organisations solicit innovative solutions for their problems from a community of 20,000 students and young professionals (Kreijveld, 2010: 64). The contest is challenge-based and there is a financial prize for the winning concept. This platform is not specifically targeting the public sector but many public sector organisations present challenges on issues such as traffic safety, security, inclusion and spatial planning. The platform contributes to innovative solutions for these problems.

An example of a civil society organisation is the platform Ushahidi, which obtains information from citizens about crises and situations of social unrest (Meijer and Potjer, 2019; Ansell and Miura, 2019). The platform was founded as a result of civil unrest after the 2007 presidential elections in Kenia and enabled local eyewitnesses to submit reports of violence, protests and so on. These reports were pinpointed on a map to contribute to safety and security by enabling platform visitors to avoid turmoil. Over the years, the platform has been used in other countries and for other purposes such as reporting on natural disasters.

Second, the governance perspective does not only focus on government policies but also about other issues in the public interest such as medicines for rare diseases, education programmes for our youth, accessibility of cities for physically challenged citizens, and so on. Following Dewey (1927), public problems are defined in a broad sense as the challenges and negative externalities faced by a wide range of actors, including governments, private and civil society actors. This means that the co-creation of public value is not only about co-creating government policies but also about the co-creation of public value with other civil and semi-public actors.

The following example highlights how public value is not only co-created with government. 'Patients Like Me' is a co-creation platform that is initiated and run by patient organisations. On this online data-sharing platform, patients create a health profile to upload data about their experiences, activities, mood and body measures over time to compare their situation with those of fellow patients with the same disease. On an aggregate level, patients produce data about the natural history of the disease (Frost and Massagli, 2008). Based on the data produced, patients sometimes initiate and conduct a clinical study and these activities even resulted in the falsification of a clinical trial that suggested that lithium carbonate could slow the progression of the disease amyotrophic lateral sclerosis (ALS) (Wicks et al, 2011).

\section{Integrated definition}

The various elements are integrated in the following definition: Digital platforms for co-creation of public value are platforms, supported by information and communication technologies and rules of exchange, that provide resources for its affiliates or users to flexibly engage in the creation of solutions for public problems. This broad definition forms a starting point for our theoretical exploration of digital platforms for the co-creation of public value.

The digital platform for co-creation of public value entails a radically new organisational model that is not yet well understood. Our theoretical exploration explores four 'layers' on the basis of the literature from different social and informational sciences to produce a multi-layered understanding of this new paradigm: 
(1) an understanding of the technological architecture on the basis of the literature on e-government (Janssen and Estevez, 2013), (2) an understanding of governance on the basis of the literature on public administration (Ansell and Miura, 2019; Meijer et al, 2019; Torfing et al, 2019), (3) an understanding of the incentives for users on the basis of the literature on coproduction (Alford, 2009) and on user innovation (Von Hippel, 2005) and (4) an understanding of the societal outcomes of co-creation on the basis of the literature on public value (Moore, 1995).

\section{Perspectives on co-creation platforms in the public sector}

\section{Technological architecture}

From an e-government perspective, co-creation is seen as an information problem to be solved by reducing the transaction costs of interactions (Linders, 2012; Lember et al, 2019). The technological architecture - defined as a systematic approach to addressing the dependencies among a large number of heterogeneous technological elements - is crucial (Janssen and Klievink, 2012). Before the introduction of modern information and communication technologies, coordinating a co-creation process between hundreds of geographically distributed individuals would be impossible or very costly. New technologies facilitate these interactions by drastically reducing the transaction costs. This makes it possible, for example, to co-create an encyclopaedia (Wikipedia) or an operating system (Linux) (Raymond, 1999).

The idea of government as a platform for the provision of services is viewed with optimism in the field of e-government studies (Bekkers, 2003). In their article about government as a platform, Janssen and Estevez (2013) discuss lean government as the next step after electronic government and transformative government. They argue that new technologies enable government to make a transformation to a more open and participatory model that they see as more desirable and now within reach.Janssen and Estevez (2013: S4) state: 'Citizens and business are empowered and motivated to take their responsibility in solving societal problems.'They highlight that, for governments, platforms provide a strategy to regain some level of control.

Further analyses in the e-government perspective focus on how an information architecture can facilitate the interactions between government platforms, private platforms, app developers, content and service providers and communities. In general, one can see differences here in the extent to which the architecture is open for interactions between a variety of users or whether the architecture limits these interactions (O'Reilly, 2010). The level of interaction between the various actors involved in the co-creation is sometimes rather limited while it can be quite extensive on other platforms. This key distinction can be illustrated with two examples.

An example of an architecture with limited interactions is Challenge.gov from the US government. This website offers agencies the opportunity to articulate problems that they would typically present to selected contractors rather than to a wide audience of potential innovators (Mergel and Desouza, 2013). The website presents challenges as diverse as air traffic safety, nature conservation and water infrastructure. As of December 2019, the US government had run nearly 1,000 challenges in more than 100 federal agencies. The architecture of Challenge.gov is closed in the sense that it does not encourage interaction between the various users. The competition 
approach calls for a closed model since users compete for prizes and therefore do not want to share their ideas.

An example of an architecture for open interactions is wijbouweneenwijk.nl in the Netherlands (Kreijveld, 2010). This platform supports an online community where citizens and experts meet to co-create a new residential area in the municipality of Smallingerland. The ambition of this platform was to generate collective ownership, which essentially means that the citizen can direct the design of the neighbourhood. The platform was not the only form of interaction. Ideas generated on the virtual platform were followed by face-to-face meetings that resulted in specific designs in various groups. The central focus on collective design was facilitated by a platform that is based on openness in terms of information provision, information exchange and interactions.

A key lesson from the e-government perspective, is that the information architecture underlying the platform matters since this architecture organises the relations between government, commercial actors, civil society actors and citizens. We have identified the degree of openness of the platform as a main feature. Some platforms have extensive openness and facilitate access to information and interactions with other actors while other platforms are rather closed and emphasise competition between different ideas.

\section{Governance}

While the e-government perspective highlights technological features, a public administration perspective on platforms for co-creation in the public sector puts the emphasis on the question of how relational patterns are coordinated. Governments can play different roles on digital platforms: they can develop a platform, participate in a platform, and regulate digital platforms. In our analysis, we focus on the role of government as one of the partners in the co-creation of public value and we leave out the regulatory role (for an excellent discussion:Van Dijck et al, 2018).

Ansell and Miura (2019) and Meijer et al (2019) position the rise of platforms in the public sector in a broader process of societal transformation. The first transformation, which we have already extensively discussed in this article, is that governance has become a decentred or distributed process (Koppenjan and Klijn, 2004). The second, related, transformation is the change in leadership. Meijer et al (2019) refer to organising without leadership and Ansell and Miura (2019) stress that leadership becomes more indirect, facilitative and intermediating. They indicate that platforms build upon ideas of 'meta-governance' (Sorensen and Torfing, 2009), facilitative leadership (Ansell and Gash, 2012), orchestration (Abbott et al, 2016) and intermediation (Howells, 2006). Platforms do not determine the outcomes of interactions but condition these through rules, incentives and framing to steer the interactions on the platform in the direction of certain types of public value. The third transformation that Ansell and Miura (2019) present is the growing appreciation that the public sector needs to be managed for emergent change (Sabel and Zeitlin, 2008; Van der Voet et al, 2014).

The overall argument that Ansell and Miura (2019) make is that the platforms provide innovation leverage and production leverage, which form the basis for their contribution to new forms of interaction such as open innovation and co-creation. The added value in the platforms lies in the reduction of transaction costs which enables governments to implement these new forms of government with distributed 
communities of citizens. Meijer et al (2019) make a similar argument about the changing nature of interactions. They also mention crowd sourced deliberation and add radical openness, citizen-centricity and connected intelligence. These features result in organisational forms that facilitate co-creation on a massive scale.

Although the platform facilitates interactions between a variety of actors, there still is one actor in control: 'the company that controls a successful platform controls the interface between players and end users, and dictates the rules of engagement' (Hagiu and Yoffie, 2009: 3). Therefore, even though the model of organisation is radically different, we can still distinguish the modes of governance enacted through the ownership of the platform as state, market and civil society. The private sector sees these platforms as a model for making profit, public sector organisations apply platforms to realise their policy objectives, and civil society organisations use platforms to engage citizens for community interests.

Private sector platforms can contribute to the co-creation of public value but they do this to make a profit. Their business model is an updated version of traditional public sector consultancy. As their customers, government organisations present problems to the platforms to find innovative solutions. These commercial platforms are successful when they are able to attract a large number of individuals and teams who provide innovative ideas. Instead of asking a consultant to develop an idea, the challenge is crowd-sourced to find an innovative solution (Boudreau et al, 2011; Lakhani et al, 2013). In doing so, they create an online community (Barrett et al, 2016) that can vary in the degree of how active its members are, ranging from mere brand-awareness (Ramaswamy and Ozcan, 2016) to active idea-generating platforms.

A variety of public sector platforms have been developed to facilitate the co-creation of public value. Some of these platforms have a specific focus on finding a solution for a specific problem whereas others offer a wide range of unfocused problems. Even though sometimes financial incentives are provided to citizens (for example, Challenge.gov), these platforms should be understood as an extension of the logic of citizen participation. Torfing et al (2019: 804) highlight that co-creation extends the logic of participation by strengthening not only the democratic influence but also fostering citizen contributions to effective solutions to shared problems.

Civil society platforms present a 'third logic' to the interactions on platforms: neither state nor private sector. These organisations serve 'the domain which falls between the private realm of the family on the one hand and the state on the other' (Dunn and Hann, 1996: 27). Civil society organisations focus on specific interests and the platforms serve to accentuate or further develop that interest. The key example of a civil society platform is Wikipedia. Thousands of users collaborate in Wikipedia to develop an encyclopaedia where the basic motive is altruism (or social status). Meijer (2011; 2012) provides examples of platforms as virtual civil society communities highlighting that these new technologies enable citizens to form new types of organisations.

This overview highlights that even though a variety of actors are involved in the co-creation process, the platform owners play a specific role in the process since they set the rules for the interaction. These forms of indirect, facilitative and intermediating leadership (Ansell and Miura, 2019) set the conditions for co-creation. We identified three main forms of governance - market, state and civil society - and indicated key differences between these modes of governance. 


\section{Users}

The governance of the platform may be well-organised, but it only works when there is an active community of users. Innovation studies have been investigating the role of users in product and service development (for example, Von Hippel, 1988; Oudshoorn and Pinch, 2003; Lüthje, 2004). Usually, the user innovation literature explores the extent to which users are engaged in improving products, such as medical devices (Von Hippel, 1988; Keinz et al (2012), or services, such as outdoor sports products (Franke and Shah, 2003), and the ways in which users are engaged in this process. This scope has been widened, in the sense that organised cooperation takes into account users who work together on novel products and services in the context of communities (Von Hippel, 2005).

User communities may take the form of virtual platforms where they share information and practices (Van Oost et al, 2008; Hyysalo et al,2018). An example is the online community of IKEA furniture hackers (Grabher and Ibert, 2013). Community members invest private resources to contribute to the community by developing prototypes or validating ideas by others. These contributions are then freely revealed to the community, by this characterising such a community as a 'private-collective' innovation model (Von Hippel and Von Krogh, 2003). Unsurprisingly, a great deal of research on collective action - specifically also on innovation user communities - such as open source software communities, has focused on incentives to contribute (Dahlander and Magnussen, 2005). In the last decade, there has also been a rising interest in crowd-sourcing user communities, in which users are asked to contribute their ideas to specific challenges (Lakhani et al, 2013).

The reasons for the platform's users - the actors that generate the ideas - to participate are different. Some users are driven by profit and capitalise on a knowledge advantage (for example, the Battle of Concepts platform mentioned earlier; Grabher et al, 2008) while others are motivated by the will to bring improvements to their own area (for example, Verbeterdebuurt) or by the desire to broadly contribute to the public cause. There are even contributors who see it as a career opportunity (Lerner and Tirole, 2002) or as a way to boost their reputation in a community of peers (Stewart, 2005).

\section{Societal outcomes}

The final issue is whether all the interactions between the variety of users on a digital platform actually contribute to public value. Surprisingly little is known about the outcomes of processes of co-creation. After conducting an extensive literature review, Voorberg, Bekkers and Tummers (2015:1344) concluded that only a small number of studies actually addressed outcomes and most of these studies focused on effectiveness. The majority of the studies seemed to consider co-creation as a virtue in itself and focused on the factors that influence co-creation rather than on the outcomes.

For a comprehensive assessment of co-creation on digital platforms, a broad perspective on the contribution of public value is needed (Moore, 1995; Bryson et al, 2014). Co-creation can result in desirable outcomes - positive public value, but also in undesirable outcomes - such as negative public value impingements on the privacy of people, decline of sustainability, les security, unfair treatments and so on. Moore (2014) discusses the idea of public value accounting, which basically means 
that the benefits and costs in terms of public value can be calculated to determine preferred actions.

The relation between platform interactions and public value is, as we have seen in recent debates about AirBnB, quite complex (Frenken and Schor, 2017). While individual interactions such as renting an apartment seem harmless, collective practices may result in a host of negative effects on cities such as rising rents and declining social cohesion. This means that the outcomes should not only be understood as resulting from the objectives of the platform owner but rather as emerging from the variety of interactions between the visitors to the platform (Kornberger et al, 2017).

This overview highlights that public value can be realised through processes of co-creation facilitated by digital platforms. The result is not necessarily positive since co-creation can also result in negative public value. The focus on public value can be rather broad (when the platform facilitates all kinds of interactions) or rather small (when there is a focus on a specific issue). The outcomes are often emergent from the complex interactions on a platform rather than determined by the objectives of the platform owner.

\section{Towards a multi-layered perspective}

The insights from the literature that we discussed can now be used to develop a multilayered perspective on platforms for co-creation in the public sector. The perspective that we develop consists of four layers (see Figure 1):

1. Technological layer The facilities that are offered by the technological architecture of the platform - leverage (Ansell and Miura, 2019), affordances (Hutchby, 2001; Deibert, 1997) - are conditioned by technological features. The discipline of e-government helps us to develop a sound understanding of the architecture underlying the co-creation platforms (Janssen and Estevez, 2013; Jukic and Merlak, 2017). A key aspect is the extent to which the architecture facilitates open interactions between a variety of users.

2. Governance layer The way the platform is used to realise certain objectives, the ownership of the platform, the types of interactions and so on are all part of the governance layer.The discipline of public administration focuses on this layer.The key issue here is whether the platform is governed by a commercial organisation and follows an economic logic, or by a government organisation with a state logic of a non-profit organisation which follows a civil society logic (Nutt, 2000).

Figure 1: Layer model of digital platforms for co-creation

\begin{tabular}{|c|c|}
\hline \multicolumn{2}{|c|}{ Societal layer } \\
Narrow or broad public value? \\
\hline Governance layer \\
Public, private or civil society platform? & Individual user layer \\
\hline \multicolumn{2}{|c|}{ Technological layer } \\
Open or closed architecture? \\
\hline
\end{tabular}


3. Individual users layer The platform will only develop value if individual users have the incentive to actually use the platform to co-create solutions for public problems. Theories about user innovation (Von Hippel, 2005) but also about coproduction (Alford, 2009) help to understand this layer and the incentive structures of individuals. In general, we can make a distinction between individual incentives, groups incentives and public incentives for co-creation in the public sector.

4. Societal layerThe societal layer focuses on the consequences of the use of platforms for broader societal relations and outcomes. Questions about inclusion and exclusion are crucial here. The literature on public value (Moore, 1995; Moore, 2014; Bryson et al, 2014) can provide important inputs for understanding this layer. The key distinction here is between platforms for specific forms of public value and digital platforms that broadly facilitate the co-creation of public value.

The four layers are presented in an integrated model in Figure 1.

The multi-layered model that we have developed highlights both the different layers and the interfaces between the layers. This means that this model facilitates both critical analyses (how do co-creation platforms influence societal structures?) and instrumental analyses (which type of architecture is needed for a specific governance model?) and thus provides a rich lens for understanding digital platforms for co-creation in the public sector. An analysis of linkages between the elements can form the basis for developing a further understanding of digital platforms. In general, we can think of three basic configurations: (1) a closed platform, controlled by a private sector organisation with a focus on individual incentives and narrow, often economics-driven public values; (2) an open platform, controlled by a government organisation with a focus on public incentives and broad public, democratic values; and (3) an open platform run by a civil society organisation with a focus on intermediate public, community value. We can present examples of these three types of organisations.

The closed platform controlled by a private sector organisation - the first configuration - is dominant in the expanding literature on platforms (Frenken and Schor, 2017; Van Dijck et al, 2018). This literature mostly highlights risks to public value but there are also examples of platforms that build upon private incentives to generate public value. An example of this configuration is the American private-sector platform InnoCentive. The platform was founded by former employees of the pharmaceutical company Eli Lilly and initial investors include the Rockefeller Foundation. Through this foundation, many semi-public challenges have been articulated, especially on research in the field of poverty-related diseases. The challenge to find a biomarker to track the progression of the rare disease amyotrophic lateral sclerosis (ALS), organised together with the non-profit innovation organisation Prize4Life, attracted much attention.

The government platform which focuses on broad citizen engagement - the second configuration - is prevalent in the rich literature on new forms of citizen engagement with a growing number of publications on collaborative rule- and law-making (Da Conceição Rossini and de Oliveira, 2016; Perez et al, 2018). An example is the platform Internetconsultatie.nl in the Netherlands (Edwards and Kool, 2015). This website provides information about proposed new legislation and invites citizens to provide feedback and input for this legislative process. The agency that presents the proposal on the website also presents specific issues for feedback from citizens. 
Citizens have access to a variety of documents related to the proposal (for example, research reports, data from the National Agency for Statistics, and also to the reactions of other citizens).

The open platform run by civil society organisations - the third configuration - is popular in media studies. In analyses that highlight the limitations of state and market domination of digital platforms, much is expected from CSOs (Van Dijck et al, 2018; Meijer and Potjer, 2019). An example of this configuration is the Open Knowledge Labs that are organised across Germany by the Open Knowledge Foundation. The labs run a website as well as physical meeting places where they organise hackathons in which coders, designers and citizens participate. The projects and hackathons focus on gaining access to and visualisation of open data. Many projects have a political or activist angle. Examples include showing where houses are vacant, how many trees or children's playgrounds are present in certain streets, and which pollutants are present in tap water.

The fact that we have identified these configurations does not mean that no 'hybrid configurations' can exist. An example of such as hybrid is Challenge. gov (see the subsection on technological architecture in the third section). This government platform indeed applies a private sector logic that is similar to the Battle of Concepts platform in the Netherlands, closed architecture, individual incentives and narrow public value. Another hybrid is the platform 'Verbeterdebuurt' (Improve the Neighbourhood), also in the Netherlands (Meijer and Potjer, 2019). Although this platform largely focuses on coproduction of public maintenance - for example, reporting on broken streetlights and road quality - it also provides opportunities for co-creating ideas. This platform is a hybrid in the sense that it is a private sector platform but provides opportunities for open interactions and focuses on public incentives.

The (hybrid) configuration highlight how the framework can be used to analyse the different layers and also the interfaces between the layers. A key empirical question is when these platforms succeed in realising the desired user interactions. According to theoretical approaches such as Strategic Business Alignment (Henderson and Venkatraman, 1993), success of organisational action depends to a large extent on the alignment between different organisational components. The alignment indeed needs to be studied empirically to identify configurations that produce public value but also understand how and when negative value is produced. The question is whether we indeed find that there needs to be a fit between the layers to produce public value and limit negative public value. According to the idea of alignment, this is bound to result in less effectiveness, but whether this is really the case is a question that needs to be answered through empirical research.

\section{Conclusions and research agenda}

Both in the academic literature and in public administration practice there is growing attention for the idea that digital platforms generate public value. Some authors even argue that these platforms have a good fit with the new governance paradigm that is emerging, which puts emphasis on co-creation as a core activity in the relations between various actors in the public sector. A key feature of this new paradigm is that the public sector is seen as a place where politicians exercise facilitative leadership and citizens are partners in the generation of solutions for a variety of problems and 
issues (Torfing et al, 2019). The diverse interactions patterns that form a key element of this new paradigm can readily be supported by digital platforms.

This article set out to develop a theoretical understanding of digital platforms for co-creating public value with the following question to guide our journey: how can we understand the potential contribution of digital platforms to the co-creation of public value? We build a theoretical understanding not only on the literature on public administration but also on e-government and innovation. We used the literature to identify four layers for understanding digital platforms for the co-creation of public value: technology, governance, users and societal value. We used these four layers to identify three basic configurations: (1) a closed platform, controlled by a private sector organisation with a focus on individual incentives and narrow public values; (2) an open platform, controlled by a government organisation with a focus on public incentives and broad public value; and (3) an open platform, run by a civil society organisation with a focus on intermediate public value and also highlighted that hybrid configurations can exist. These configurations can be regarded as answers to the question how digital platforms can contribute to public sector co-creation.

The multi-layered approach forms a basis for further theoretical exploration of digital platforms for the co-creation of public value. In future work, the different elements can be explored further on the basis of not only notions that are already quite well known to scholars of public administration such as managing common pool resources (Ostrom, 1990), but also notions from other fields such as connective intelligence (De Kerckhove, 2001) and network dynamics (Barabasi, 2003). Platforms present a fundamentally different organisational model for the public sector and substantive theoretical work is needed to properly position and understand this new model.

The framework can form the basis for three lines of research into digital platforms for co-creating public value: to map different configurations, to analyse the relation between configuration and societal impact and to position platforms in complex societal systems of public value creation. First, the layers can be used to systematically describe the population of digital platforms for co-creation in the public sector. We can map to what extent we find more open or closed platforms, more government, private sector or civil society platforms, more individual, group or public incentives and more narrow or broad public values and to check whether we find more platforms in the basic configurations or whether more hybrid configurations can be found. Second, the societal impact of the configurations can be analysed to explain differences in the production of public value between the various configurations and to test whether the assumption of alignment indeed plays a role in understanding the contribution of platforms to public value co-creation. Third, platforms as a key dimension of complex social system can be investigated as one dimension of the provision of solutions to public challenges, positioned next to design of public service offerings, individual organisations and their resources, governance networks and societal context. This research agenda will result in a theoretical and empirical understanding of digital platforms for the co-creation of public value that is based on a configurational understanding of these practices.

In sum, this article provides a theoretical understanding of digital platforms for the co-creation of public value that is not normative - it neither supports nor rejects the idea of these platforms - but positions that idea in the broader literature that aims to provide an understanding of these practices as a new paradigm. A key observation 
in this article is that the paradigm is new in the sense that it is built upon horizontal and parallel social interactions, that are supported by new technological opportunities, yet still relies on a basic understanding of the public sector as being the result of commercial, state and civil society organisations.

\section{Conflict of interest}

The authors declare that there is no conflict of interest.

\section{References}

Abbott, K.W., Genschel, P., Snidal, D. and Zangl, B. (2016) Two logics of indirect governance: Delegation and orchestration, British Journal of Political Science, 46(4): 719-29.

Acquier,A., Daudigeos, T. and Pinkse, J. (2017) Promises and paradoxes of the sharing economy: an organizing framework, Technological Forecasting and Social Change, 125: 1-10. doi: 10.1016/j.techfore.2017.07.006

Al-Ani, A. (2017) Government as a platform: services, participation and policies, in A. Kamalipour,Y. and M. Friedrichsen (eds) Digital Transformation in Journalism and News Media: Media Management, Media Convergence and Globalization, Boston, MA: Springer International Publishing, pp 179-96.

Alford, J. (2009) Engaging Public Sector Clients: From Service-Delivery to Co-Production, Basingstoke: Palgrave Macmillan.

Alford, J. and Hughes, O. (2008) Public value pragmatism as the next phase of public management, The American Review of Public Administration, 38(2): 130-48. doi: $10.1177 / 0275074008314203$

Ansell, C. and Miura, S. (2019) Can the power of platforms be harnessed for governance?, Public Administration, 98(1): 261-76. doi: 10.1111/padm.12636

Ansell, C. and Gash, A. (2012) Stewards, mediators, and catalysts: toward a model of collaborative leadership, Innovation Journal, 17(1): article 7.

Barabasi, A.L. (2003) Linked: How Everything is Connected to Everything Else and What it Means, New York: Plume.

Barrett, M., Oborn, E. and Orlikowski,W. (2016) Creating value in online communities: the sociomaterial configuring of strategy, platform, and stakeholder engagement, Information Systems Research, 27(4): 704-23. doi: 10.1287/isre.2016.0648

Bekkers, V. (2003) E-government and the emergence of virtual organizations in the public sector, Information Polity, 8(3/4): 89-101.

Boudreau, K.J., Lacetera, N. and Lakhani, K.R. (2011) Incentives and problem uncertainty in innovation contests: an empirical analysis, Management Science, 57(5): 843-63. doi: 10.1287/mnsc.1110.1322

Bryson,J.M., Crosby, B.C. and Bloomberg, L. (2014) Public value governance: moving beyond traditional public administration and the new public management, Public Administration Review, 74(4): 445-56. doi: 10.1111/puar.12238

Da Conceição Rossini, P.G. and de Oliveira,V.V. (2016) E-democracy and collaborative lawmaking: the discussion of the political reform in Brazil, International Journal of Communication, 10(21): 4620-40.

Dahlander, L. and Magnusson, M.G. (2005) Relationships between open source software companies and communities: Observations from Nordic firms, Research Policy, 34(4): 481-93. doi: 10.1016/j.respol.2005.02.003 
De Kerckhove, D. (2001) The Architecture of Intelligence, Basel: Springer Science and Business Media.

Deibert, R.D. (1997) Parchment, Printing and Hypermedia, New York: Columbia University Press.

Dewey, J. (1927) The Public and Its Problems, Chicago, IL: Swallow Press.

Dunn, E. and Hann, C. (1996) Civil Society: Challenging Western Models, London: Routledge.

Edwards, A.R. and de Kool, D. (2015) Kansen En Dilemma's Van Digitale Democratie: Wat Kan Digitale Burgerbetrokkenheid Betekenen Voor Het Nederlandse Parlement, The Hague: Rathenau Instituut.

Franke, N. and Shah, S. (2003) How communities support innovative activities: an exploration of assistance and sharing among end-users, Research Policy, 32(1): 157-78. doi: 10.1016/S0048-7333(02)00006-9

Frenken, K. and Schor, J.B. (2017) Putting the sharing economy into perspective, Environmental Innovation and Societal Transitions, 23(June): 3-10, http://doi. org/10.1016/J.EIST.2017.01.003. doi: 10.1016/j.eist.2017.01.003

Frost, J. and Massagli, M. (2008) Social uses of personal health information within PatientsLikeMe, an online patient community: what can happen when patients have access to one another's data, Journal of Medical Internet Research, 10(3): e15. doi: 10.2196/jmir.1053

Gawer, A. (2014) Bridging differing perspectives on technological platforms: toward an integrative framework, Research Policy, 43(7): 1239-49, doi: 10.1016/j. respol.2014.03.006.

Grabher, G. and Ibert, O. (2013) Distance as asset? Knowledge collaboration in hybrid virtual communities, Journal of Economic Geography, 14(1): 97-123. doi: 10.1093/ jeg/lbt014

Grabher, G., Ibert, O. and Flohr, S. (2008) The neglected king: the customer in the new knowledge ecology of innovation, Economic Geography, 84(3): 253-80. doi: 10.1111/j.1944-8287.2008.tb00365.x

Hagiu,A. and Wright, J. (2015) Multi-sided platforms, Harvard Business School Working Paper, pp 15-37.

Hagiu, A. and Yoffie, D.B. (2009) What's your Google strategy?, Harvard Business Review, 87(4): 74-81.

Henderson, J.C. and Venkatraman, N. (1993) Strategic alignment: leveraging information technology for transforming organizations, IBM Systems Journal, 32(1): 4-16. doi: 10.1147/sj.382.0472

Howells, J. (2006) Intermediation and the role of intermediaries in innovation, Research policy, 35(5): 715-28.

Hutchby, I. (2001) Conversation and Technology: From the Telephone to the Internet, Cambridge: Polity.

Hyysalo, S., Juntunen, J.K. and Martiskainen, M. (2018) Energy internet forums as acceleration phase transition intermediaries, Research Policy, 47(5): 872-85. doi: 10.1016/j.respol.2018.02.012

Janssen, M. and Estevez, E. (2013) Lean government and platform-based governance: doing more with less, Government Information Quarterly, 30: S1-S8. doi: 10.1016/j. giq.2012.06.009 
Janssen, M. and Klievink, B. (2012) Can enterprise architectures reduce failure in development projects?, Transforming Government: People, Process and Policy, 6(1):27-40. doi: 10.1108/17506161211214804

Jukic, T. and Merlak, M. (2017) The use of social networking sites in public administration: the case of Slovenia, Electronic Journal of E-Government, 15(1): 2.

Keinz, P., Hienerth, C.. and Lettl, C. (2012) Designing the organization for user innovation, Journal of Organization Design, 1(3): 20-36.

Kenney, M. and Zysman, J. (2015) Choosing a future in the platform economy: the implications and consequences of digital platforms, Discussion paper at Kauffman Foundation New Entrepreneurial Growth Conference, 18-19 June,Amelia Island, FL, pp 156-60.

Kenney, M. and Zysman, J. (2016) The rise of the platform economy, Issues in Science and Technology, 32(3): 61-9.

Kenney, M., Rouvinen, P., Seppälä,T. and Zysman, J. (2019) Platforms and industrial change, Industry and Innovation, 26(8): 871-9.

Koppenjan,J.F.M. and Klijn, E.H. (2004) Managing Uncertainties in Networks: A Network Approach to Problem Solving and Decision Making, London: Routledge.

Kornberger, M., Pflueger, D. and Mouritsen, J. (2017) Evaluative infrastructures: accounting for platform organization, Accounting, Organizations and Society, 60(C): 79-95. doi: 10.1016/j.aos.2017.05.002

Kreijveld, M. (2010) Unlocking the full potential of the crowd: a government perspective, in R. in 'tVeld (ed) Knowledge Democracy, Berlin/Heidelberg: Springer, pp 63-72.

Lakhani, K.R., Boudreau, K.J., Loh, P.R., Backstrom, L., Baldwin, C., Lonstein, E. and Guinan, E.C. (2013) Prize-based contests can provide solutions to computational biology problems, Nature Biotechnology, 31(2): 108. doi: 10.1038/nbt.2495

Lember, V., Brandsen, T. and Tõnurist, P. (2019) The potential impacts of digital technologies on co-production and co-creation, Public Management Review, 21(11): 1665-86, doi: 10.1080/ 14719037.2019.1619807.

Lerner, J. and Tirole, J. (2002) Some simple economies of open source, Journal of Industrial Economics, 50(2): 633-49.

Linders, D. (2012) From e-government to we-government: defining a typology for citizen coproduction in the age of social media, Government Information Quarterly, 29(4): 446-54.

Lüthje, C. (2004) Characteristics of innovating users in a consumer goods field: an empirical study of sport-related product consumers, Technovation, 24(9): 683-95.

Meijer,A.J. (2011) Networked coproduction of public services in virtual communities, Public Administration Review, 71(4):598-607.doi:10.1111/j.1540-6210.2011.02391.x

Meijer,A.J. (2012) Co-production in an information age: individual and community engagement supported by new media, Voluntas, 23: 1156-72. doi: 10.1007/ s11266-012-9311-z

Meijer, A. and Potjer, S. (2019) Citizen-generated open data: an explorative analysis of 25 cases, Government Information Quarterly, 35(4): 613-21. doi: 10.1016/j. giq.2018.10.004

Meijer, A.J., Lips, M. and Chen, K. (2019) Open governance: a new paradigm for understanding urban governance in an information age, Frontiers in Sustainable Cities, https://doi.org/10.3389/frsc.2019.00003. 
Mergel, I. and Desouza, K.C. (2013) Implementing open innovation in the public sector: the case of Challenge.gov, Public Administration Review, 73(6): 882-90. doi: 10.1111/puar.12141

Moore, M.H. (1995) Creating Public Value: Strategic Management in Government, Cambridge, MA: Harvard University Press.

Moore, M.H. (2014) Public value accounting: establishing the philosophical basis, Public Administration Review, 74(4): 465-77. doi: 10.1111/puar.12198

Nutt, P.C. (2000) Decision-making success in public, private and third sector organizations: finding sector dependent best practice, Journal of Management Studies, 37(1): 77-108.

O'Reilly,T. (2010) Government as a platform, in D. Lathrop and L. Ruma (eds) Open Government: Collaboration, Transparency, and Participation in Practice, San Francisco, CA: O'Reilly Media, pp 11-40.

Osborne, S.P. (2018) From public service-dominant logic to public service logic: are public service organizations capable of co-production and value co-creation?, Public Management Review, 20(2): 225-31. doi: 10.1080/14719037.2017.1350461

Ostrom, E. (1990) Governing the Commons: The Evolution of Institutions for Collective Action, Cambridge: Cambridge University Press.

Oudshoorn, N. and Pinch, T. (eds) (2003) How Users Matter: The Co-construction of Users and Technologies, New Baskerville, MA: The MIT Press.

Perez, O., Bar-Ilan, J., Gazit, T., Aharony, N., Amichai-Hamburger, Y. and Bronstein, J. (2018) The prospects of e-democracy: an experimental study of collaborative e-rulemaking, Journal of Information Technology \& Politics, 15(3): 278-99.

Prahalad, C.K. and Ramaswamy,V. (2004) The Future of Competition: Co-creating Unique Value with Customers, Cambridge, MA: Harvard Business Press.

Ramaswamy,V. and Ozcan, K. (2016) Brand value co-creation in a digitalized world: an integrative framework and research implications, International Journal of Research in Marketing, 33(1): 93-106. doi: 10.1016/j.ijresmar.2015.07.001

Raymond, E.S. (1999) The cathedral and the bazaar, Knowledge, Technology \& Policy, 12(3): 23-49. doi: 10.1007/s12130-999-1026-0

Rochet,J.C. and Tirole, J. (2003) Platform competition in two-sided markets, Journal of the European Economic Association, 1(4):990-1029. doi:10.1162/154247603322493212

Scaraboto, D. (2015) Selling, sharing, and everything in between: the hybrid economies of collaborative networks, Journal of Consumer Research, 42(1): 152-76, http://doi. org/10.1093/jcr/ucv004. doi: 10.1093/jcr/ucv004

Sabel, C.F. and Zeitlin, J. (2008) Learning from difference: the new architecture of experimentalist governance in the EU, European Law Journal, 14(3): 271-327.

Stewart, D. (2005) Social status in an open-source community, American Sociological Review, 70(5): 823-42. doi: 10.1177/000312240507000505

Sørensen, E. and Torfing, J. (2009) Making governance networks effective and democratic through metagovernance, Public Administration, 87(2): 234-58.

Torfing, J., Sørensen, E. and Røiseland,A. (2019) Transforming the public sector into an arena for co-creation: barriers, drivers, benefits, and ways forward, Administration \& Society, 51(5): 795-825. doi: 10.1177/0095399716680057

Van Dijck, J. (2013) The Culture of Connectivity:A Critical History of Social Media, Oxford: Oxford University Press.

Van Dijck, J., Poell, T. and De Waal, M. (2018) The Platform Society: Public Values in A Connective World, Oxford: Oxford University Press. 
Van derVoet, J., Groeneveld, S. and Kuipers, B.S. (2014) Talking the talk or walking the walk? The leadership of planned and emergent change in a public organization, Journal of Change Management, 14(2): 171-91.

Van Oost, E., Verhaegh, S. and Oudshoorn, N. (2008) From innovation community to community innovation: user-initiated innovation in wireless Leiden, Science, Technology \& Human Values, 34(2): 182-205.

Von Hippel, E. (1988) The Sources of Innovation, Oxford: Oxford University Press.

Von Hippel, E. (2005) Democratizing Innovation, Cambridge, MA: MIT Press.

Von Hippel, E. and von Krogh, G. (2003) Open source software and the 'privatecollective' innovation model: issues for organization science, Organization Science, 14(2): 209-23. doi: 10.1287/orsc.14.2.209.14992

Voorberg, W.H., Bekkers, V.J. and Tummers, L.G. (2015) A systematic review of co-creation and co-production: embarking on the social innovation journey, Public Management Review, 17(9): 1333-57. doi: 10.1080/14719037.2014.930505

Wicks, P., Vaughan, T.E., Massagli, M.P. and Heywood, J. (2011) Accelerated clinical discovery using self-reported patient data collected online and a patient-matching algorithm, Nature Biotechnology, 29(5): 411. doi: 10.1038/nbt.1837 